\title{
Commentary: Women's Sexual and Reproductive Health and Public Health Crisis
}

\author{
Raquel Zanatta Coutinho* \\ Department of Demography, Federal University of Minas Gerais, Brazil \\ *Corresponding author: Raquel Zanatta Coutinho, Department of Demography, Federal University of Minas Gerais, Brazil
}

Received: March 22, 2021; Accepted: April 05, 2021; Published: April 14, 2021

Soon after the Zika virus hit Brazil, in 2015, cases of Congenital Zika Syndrome (CZS), for which the most known consequence is microcephaly, exploded. One unique feature of this virus is its capability of being transmitted by both the Aedes aegypti mosquito, a long known vector for Brazilians, and by unprotected sexual intercourse. The epidemic was soon declared a Public health Emergency of International Concern and amidst informal recommendations for pregnancy delays, little was known about how women were navigating the crisis. Knowing that half of the pregnancies are unplanned in Brazil, it was difficult to imagine that most women would be able to comply with the recommendation.

Our qualitative research, in the field in mid-2016, illuminated women's reproductive intention and behavior during those first months and revealed a general desire for pregnancy postponement [1-3]. Nevertheless, major sociodemographic differences were also noticed as older women revealed not being able to wait any longer to conceive due to biological reasons, and while socioeconomically advantaged women report having the tools to minimize the risk of infection, socioeconomically vulnerable women reported higher exposure to mosquito bites (due to inadequate infrastructure, an intermittent water supply that mandates water storage inside the households and lack of sanitation network). The latter also reported lower power of negotiation to enforce condom use and barriers to contraceptive access.

When the data on live births finally became available, the decline in births we observed following the 9 month period after the PAHO declaration could not be ignored. Our research explored the data and found that in fact, highly educated, especially younger, were the group for whom fertility rates declined more steeply. We also found geographic variation suggesting proximity to microcephaly cases was linked to higher declines. Nevertheless, in our focus groups, we noticed women were generally not aware of sexual transmission and complained about being the solo responsible for preventing mosquito bites.

Digging into public health communication campaigns to raise awareness about Zika, we found campaigns largely focused on mosquito transmission and on women's responsibility for applying measures of personal care against bites, such as wearing longsleeved clothing, plants, and repellents. Although those measures are important, women could get infected through their sexual partners during unprotected intercourse even if they followed all measures of care. Besides, non-pregnant women were not a focus of campaigns regardless of the high number of unplanned pregnancies registered in the country. Unplanned pregnancies, in the case of Zika, could delay the point at which women start to apply measures of protection. Men and other persons who share a household with a pregnant woman or women at risk of pregnancy were completely neglected from the responsibility of caring for themselves. Contraceptive management, especially the importance of condom negotiation, was mentioned in only 3 out of 94 communication pieces. No conversation about gender inequality in the allocation of responsibilities was established despite the scientific call made by gender scholars when the epidemics were still ongoing.

In early 2020, Covid-19 started to spread. While vaccines were still being prepared or until it is not a reality for the majority of the population, social distancing and lockdown proved to be the most effective measures to contain the spread of the disease and prevent the collapse of health systems due to an excess of demand for care and hospitalization. The prevalence of modern contraceptives in developed countries and countries with low fertility - such as Brazil is too high to expect large proportion s of unplanned pregnancies due to new living arrangements brought up by Covid-19. Nevertheless, for some women, loss of access to sexual and reproductive health services, and possible increase of gender violence could contribute to an increase in unplanned pregnancies. As well as happened during the Zika epidemics, this is a result that is unfortunately expected for the low-income, low-educated women, women in regional areas, indigenous and black women, the most vulnerable in the social scale.

The first babies made during Covid-19 are now being born. As we are anxiously waiting for the official data on live births to be released, we count the number of deaths in Brazil: 287,795 in March 19 2021 and increasing levels of infections, despite the start of the vaccination. Research questions that we will pursue in the next months are: will growth rates be impacted by declining fertility rates as well as by the death rates? Who are the women whose reproductive plans were most affected by Covid-19? How and for what means were they affected? How are these differences felt by women of different races, SES, and age groups? 
We are observing the changing natures of the public health crisis, but a perpetuation of unique consequences for women, especially the most vulnerable, due to negligence and lack of priority in politics of sexual and reproductive health. We urge for politics that protect the health and wellbeing of women of reproductive age and their offsprings.

\section{References}

1. Coutinho RZ, Montalvo AV, Weitzman A, et al. (2021) Zika virus public health crisis and the perpetuation of gender inequality in Brazil. Reprod Health 18: 40.

2. Marteleto LJ, Weitzman A, Coutinho RZ, Alves SV (2017) Women's reproductive intentions and behaviors during the Zika epidemic in Brazil. Popul Dev Rev 43: 199227. [crossref]

3. Marteleto LJ, Guedes G, Coutinho RZ, Weitzman A (2020) Live births and fertility amid the zika epidemic in Brazil. Demography 57: 843-872. [crossref] 